\title{
Effect of preoperative renal function on long-term survival after cardiac surgery
}

\author{
Jayesh Dhanani, MBBS, MD, FCICM, Daniel V. Mullany, FCICM, FANZCA, MBBS, M Med Sci \\ (Clin Epi), and John F. Fraser, MB ChB, PhD, MRCP, FRCA, FFARCSI, FCICM
}

\begin{abstract}
Objectives: The study objective was to investigate the effect of renal failure on intermediate-term survival in cardiac surgery patients.
\end{abstract}

\begin{abstract}
Methods: All patients aged 18 years or older undergoing coronary artery bypass grafting, valvular surgery, thoracic aortic surgery, or a combination of these from January 1, 2002 to December 1, 2005 were included. Data were obtained from the cardiac surgery and intensive care databases. Using a matching algorithm, the date of death was obtained from the National Death Index. The simplified Medical Diet for Renal Disease formula was used to calculate the estimated glomerular filtration rate, and the patients were stratified accordingly. An estimation of the effect of the preoperative renal function on the interval to death was determined using Cox regression analysis with and without cubic splines and polynomial regression. The long-term survival was described using the Kaplan-Meier product limit method.
\end{abstract}

Results: A total of 5297 patients were included in the present study. The vital status of all patients was obtained at a mean of 2.9 years (range, 1-5) postoperatively. The actuarial 1 -year survival rate was $96 \% \pm 1 \%$, and the 3 -year survival rate was $92 \% \pm 1 \%$. The greatest early mortality occurred in the severe renal dysfunction group; however, the dialysis-dependent renal failure group showed increased mortality over time compared with the other groups. The lowest risk of death (longest interval to death) occurred with an estimated glomerular filtration rate of approximately $90 \mathrm{~mL} / \mathrm{min} / 1.73 \mathrm{~m}^{2}$.

Conclusions: The results of our study have shown that preoperative renal dysfunction is an independent predictor of long-term mortality in cardiac surgery patients. (J Thorac Cardiovasc Surg 2013;146:90-5)

Chronic kidney disease (CKD) has been seen to independently increase the risk of acute coronary syndrome, angina, coronary artery disease, stroke, and heart failure. ${ }^{1}$ Poorer renal function has been associated with an increased risk of cardiovascular events. ${ }^{2}$ The incidence of CKD is increasing worldwide, with the number of new patients requiring dialysis increasing at $7 \%$ annually. ${ }^{3}$ Almost one half of all patients beginning dialysis during a 12-year period have some form of cardiac or vascular disease, indicating the development of cardiovascular disease before the need for dialysis. ${ }^{4}$

Risk adjustment models such as the European System for Cardiac Operative Risk Evaluation (euroSCORE), ${ }^{5}$ euroSCORE II, ${ }^{6}$ and the Society of Thoracic Surgeons database ${ }^{7}$

From the Department of Intensive Care Medicine, Prince Charles Hospital, Brisbane, Queensland, Australia; and Critical Care Research Group, University of Queensland, Brisbane, Queensland, Australia.

Disclosures: Authors have nothing to disclose with regard to commercial support.

Received for publication March 20, 2012; revisions received May 24, 2012; accepted for publication June 15, 2012; available ahead of print July 27, 2012.

Address for reprints: Jayesh Dhanani, MBBS, MD, FCICM, Department of Intensive Care Medicine, Prince Charles Hospital, Rode Road, Chermside, Queensland 4032

Australia (E-mail: jayesh_dhanani@health.qld.gov.au). 0022-5223/\$36.00

Crown Copyright $\odot 2013$ Published by Elsevier Inc. on behalf of The American Association for Thoracic Surgery

http://dx.doi.org/10.1016/j.jtcvs.2012.06.037 have identified renal dysfunction as a risk factor for poor short-term outcomes.

The glomerular filtration rate (GFR) is considered to be a more accurate measure of renal function compared with the serum creatinine level. ${ }^{8}$ Of the various methods available to estimate the GFR, the Modification of Diet for Renal Disease (MDRD) formula has been shown to be more accurate and reliable. ${ }^{9}$ The simplified MDRD (sMDRD) is a simplified and validated version of the MDRD formula. ${ }^{10}$

Short-term mortality as an outcome measure has significant limitations. ${ }^{11}$ High-risk cardiac surgery and its complications can still have poor long-term outcomes, ${ }^{12}$ because the effects of surgery and critical illness can persist for 6 to 12 months and longer. ${ }^{13}$

The effect of varying degrees of renal dysfunction using the sMDRD formula on longer term survival after cardiac surgery has been less well studied. Because of these factors, the aim of the present study was to determine the effect of preoperative renal dysfunction on longer term survival in a series of patients who underwent cardiac surgery at our institution.

\section{METHODS}

A secondary data analysis of prospectively collected data from adult patients (aged $\geq 18$ years) undergoing coronary artery bypass grafting, valvular surgery, thoracic aortic surgery, or a combination of these from January 1, 2002 to December 31, 2005 was conducted. From 2002 to 2005, the data 


\section{Abbreviations and Acronyms \\ $\mathrm{CKD}=$ chronic kidney disease \\ DDRF $=$ dialysis-dependent renal failure \\ euroSCORE $=$ European System for Cardiac \\ Operative Risk Evaluation

$\begin{array}{ll}\text { eGFR } & =\text { estimated glomerular filtration rate } \\ \text { GFR } & =\text { glomerular filtration rate } \\ \text { MDRD }= & \text { Modification of Diet for Renal } \\ & \text { Disease } \\ \text { sMDRD }= & \text { simplified Modification of Diet for } \\ & \text { Renal Disease }\end{array}$

collected included medical history, cardiac risk factors, operative details, symptom status, and sufficient data to calculate the logistic euroSCORE. ${ }^{8}$ The primary outcome measure was the interval to death from any cause. Patients undergoing transplantation and ventricular assist device implantation were excluded. The Prince Charles Hospital Human Research and Ethics Committee and the Ethics Committee of the National Death Index, Australian Institute of Health and Welfare approved the present study. The approval included a waiver of informed patient consent. The patients who underwent more than 1 cardiac surgical procedure during the same hospitalization were counted as single cases. The definitions of the variables used were the same as those defined by the euroSCORE, unless otherwise specified.

The demographic and clinical data were recorded at surgery and intensive care admission by trained data collectors. The date of death was obtained from the National Death Index, Australian Institute of Health and Welfare using a matching algorithm, as previously described. ${ }^{2}$ The date of censoring was February 14, 2007, unless otherwise specified. All records were de-identified as a part of the protocol before analysis. Data quality assurance consisted of a manual review of a sample of medical records, together with hospital administrative data.

\section{Plasma Creatinine Level and Determination of Estimated GFR}

The preoperative creatinine levels, reported in micromoles per liter, were obtained as the most recent serum creatinine levels before surgery. Those values were divided by a conversion factor of 88.4 to obtain the values in milligrams per deciliter. After conversion, the upper limit for a normal plasma creatinine level was $1.13 \mathrm{mg} / \mathrm{dl}(110 \mu \mathrm{mol} / \mathrm{L})$ for women and $1.24 \mathrm{mg} / \mathrm{dL}(120 \mu \mathrm{mol} / \mathrm{L})$ for men. The estimated GFR (eGFR) was estimated using the sMDRD equation. This is a 4 -variable formula developed by Levey et $\mathrm{al}^{14}$ and adjusted for each $1.73 \mathrm{~m}^{2}$ of body surface area:

For men:

$186.3 \times$ serum creatinine level $(\mathrm{mg} / \mathrm{dL})^{(-1.154)} \times \operatorname{age}^{(-0.203)}$

For women:

$$
186.3 \times \text { serum creatinine level }(\mathrm{mg} / \mathrm{dL})^{(-1.154)} \times \text { age }^{(-0.203)} \times 0.742
$$

No correction was done for aboriginal or Torres Strait Islander ethnicity. Although no single normal value of eGFR is applicable to all patients, according to the Kidney Disease Outcomes Quality Initiative for Chronic Kidney Disease, ${ }^{15} 90 \mathrm{~mL} / \mathrm{min} / 1.73 \mathrm{~m}^{2}$ has been accepted as the normal value for patients of all ages and both genders. The GFR was categorized into greater than $90 \mathrm{~mL} / \mathrm{min}, 60$ to $89 \mathrm{~mL} / \mathrm{min}, 30$ to $59 \mathrm{~mL} / \mathrm{min}$, less than $30 \mathrm{~mL} / \mathrm{min}$, and dialysis-dependent renal failure if the patient required a preoperative dialysis program. Those patients who required acute dialysis preoperatively were classified as having a GFR less than $30 \mathrm{~mL} / \mathrm{min}$

\section{Statistical Analysis}

Normally distributed continuous data are presented as the mean \pm standard deviation and non-normal data as the median and interquartile range. Categorical data are summarized using absolute values and percentages. Long-term survival was described using the Kaplan-Meier product limit method, and comparisons were made using the log-rank statistic. Statistical analyses were performed using Stata, version 11.0 (StataCorp, College Station, Tex).

The estimation of the effect of preoperative renal function on the interval to death was determined using Cox proportional hazards regression analysis. In the multivariate preoperative model, the logistic euroSCORE was used as a single variable expressed as a percentage, and the diabetes status was included. The diabetes status, which is not contained in the euroSCORE, was categorized as no diabetes, diet-controlled diabetes, noninsulin-dependent diabetes, and insulin-dependent diabetes according to the preoperative status. A second multivariate model was created using the pre- and intraoperative variables, specifically the euroSCORE and the cardiopulmonary bypass time. The euroSCORE has recently been shown to be a good predictor of intermediate-term mortality.

\section{RESULTS}

A total of 5343 patients from 2002 to 2005 met the inclusion criteria. The data were incomplete in 46 patients of those treated from 2002 to 2005 ; thus, the detailed study cohort included 5297 patients.

In the main study sample from 2002 to 2005 , the median age was 66 years (range, 18-92). The characteristics of the patients treated from 2002 to 2005 are listed in Table 1. Important differences were present in the preoperative characteristics of the patients with severe renal dysfunction $(<30$ $\mathrm{mL} / \mathrm{min} / 1.73 \mathrm{~m}^{2}$ ) compared with those of the other groups. The patients with severe renal dysfunction were more likely to be women and to have diabetes, peripheral vascular disease, or chronic pulmonary disease. They were also more likely to have had previous myocardial infarction within 90 days. The mean predicted euroSCORE risk of death was greater for the severe renal dysfunction group. The patients with severe renal dysfunction were more likely to undergo more complex surgery than the other groups. Patients in the dialysis-dependent renal failure (DDRF) group had a greater incidence of endocarditis. Patients with mild renal dysfunction were more likely to have unstable angina.

The mean preoperative creatine level was $105 \mathrm{mmol} / \mathrm{L}$. The median eGFR was $68 \mathrm{~mL} / \mathrm{min} / 1.73 \mathrm{~m}^{2}$ (interquartile range, 56-81). The female patients had a mean eGFR of $64 \pm 23 \mathrm{~mL} / \mathrm{min} / 1.73 \mathrm{~m}^{2}$, and the male patients had a mean eGFR of $71 \pm 21 \mathrm{~mL} / \mathrm{min} / 1.73 \mathrm{~m}^{2}$.

The vital status of the patients was obtained at a mean of 2.9 years (range, 1-5) postoperatively. There were 15,467 person-years of follow-up. Of the 5297 patients, 426 died ( $8 \%$ mortality), of these deaths, 343 were after acute care discharge (Table 2). The actuarial 1-year survival rate for the sample was $96 \% \pm 1 \%$, and the 3 -year survival rate was $92 \% \pm 1 \%$. Figure 1 shows the Kaplan-Meier survival 
TABLE 1. Preoperative patient characteristics by degree of impaired renal function for 2002-2005

\begin{tabular}{|c|c|c|c|c|c|}
\hline Variable & $\begin{array}{c}\text { Normal } \\
\left(>90 \mathrm{~mL} / \mathrm{min} / 1.73 \mathrm{~m}^{2} ;\right. \\
\mathrm{n}=\mathbf{8 1 6})\end{array}$ & $\begin{array}{c}\text { Mild } \\
\left(60-90 \mathrm{~mL} / \mathrm{min} / 1.73 \mathrm{~m}^{2}\right. \\
\mathrm{n}=\mathbf{2 7 7 7})\end{array}$ & $\begin{array}{c}\text { Moderate } \\
\left(\mathbf{3 0 - 5 9} \mathrm{mL} / \mathrm{min} / 1.73 \mathrm{~m}^{2} ;\right. \\
\mathrm{n}=\mathbf{1 5 3 3}) \\
\end{array}$ & $\begin{array}{c}\text { Severe } \\
\left(<30 \mathrm{~mL} / \mathrm{min} / 1.73 \mathrm{~m}^{2} ;\right. \\
\mathbf{n}=\mathbf{1 2 0})\end{array}$ & $\begin{array}{c}\text { DDRF } \\
(\mathrm{n}=\mathbf{5 1}) \\
\end{array}$ \\
\hline Mean age (y) & 55 & 63 & 70 & 69 & 59 \\
\hline Gender ( $\%$ female $)$ & 24 & 22 & 41 & 48 & 28 \\
\hline Mean BSA $\left(\mathrm{m}^{2}\right)$ & 1.92 & 1.93 & 1.87 & 1.86 & 1.87 \\
\hline Diabetes $(\%)$ & 20.5 & 21.2 & 28.1 & 36.7 & 27.5 \\
\hline Mean serum creatinine ( $\mu$ mole/L) & 70 & 92 & 123 & 242 & 467 \\
\hline Vascular disease $(\%)$ & 7.8 & 13.1 & 20.6 & 28.3 & 17.6 \\
\hline Chronic pulmonary disease $(\%)$ & 12.9 & 12.9 & 15.6 & 16.7 & 15.7 \\
\hline Neurologic dysfunction (\%) & 1.6 & 1.3 & 2.3 & 5 & 2 \\
\hline Ejection fraction $<30 \%$ & 2.3 & 2.6 & 5.1 & 6.7 & 3.9 \\
\hline Ejection fraction $30 \%-50 \%$ & 15.3 & 18 & 21.2 & 28.3 & 23.5 \\
\hline Critical preoperative state $(\%)$ & 3.3 & 2.1 & 5.3 & 27.5 & 27.5 \\
\hline Unstable angina $(\%)$ & 6 & 4.9 & 4.8 & 2.5 & 2 \\
\hline Previous MI (\%) & 20 & 23.9 & 24.7 & 39.1 & 37.5 \\
\hline Emergency or salvage surgery $(\%)$ & 2.4 & 3 & 3.9 & 10 & 3.9 \\
\hline Reoperation $(\%)$ & 12.9 & 11 & 14.4 & 21.6 & 13.7 \\
\hline Endocarditis $(\%)$ & 2 & 1 & 1.7 & 15 & 19.6 \\
\hline Logistic euroSCORE ROD (\%) & 4.2 & 5.3 & 9.5 & 22.1 & 14.1 \\
\hline CABG $(\%)$ & 69 & 78 & 76 & 68 & 69 \\
\hline Aortic valve surgery $(\%)$ & 21 & 20 & 26 & 33 & 25 \\
\hline Mitral (\%) & 17 & 15 & 20 & 33 & 24 \\
\hline Tricuspid (\%) & 2 & 2 & 4 & 7 & 10 \\
\hline Pulmonary $(\%)$ & 1.2 & 0.4 & 0.3 & 0 & 0 \\
\hline $\begin{array}{l}\text { Thoracic aorta (including } \\
\text { ascending, arch, and } \\
\text { descending aorta) }(\%)\end{array}$ & 7 & 5 & 4 & 5 & 8 \\
\hline
\end{tabular}

$B S A$, Body surface area; $C A B G$, coronary artery bypass grafting; $D D R F$, dialysis-dependent renal failure; euroSCORE, European System for Cardiac Operative Risk Evaluation; $M I$, myocardial infarction; $R O D$, risk of death.

curves for the study sample stratified by the preoperative eGFR. The greatest early mortality occurred in the severe renal dysfunction group; however, the DDRF group showed increased mortality over time compared with the other groups. The long-term follow-up with crude mortality classified by preoperative renal dysfunction was $4.2 \%$, with 2272 person-years of follow-up in the normal group; $5.3 \%$, with 8378 person-years of follow-up in the mild group; $13 \%$, with 4388 person-years in the moderate group; $27 \%$, with 304 person-years of follow-up in the severe group; and $29 \%$, with 123 person-years of follow-up in

TABLE 2. Log-rank test for equality of survivor functions in those discharged alive from hospital

\begin{tabular}{lcc}
\hline \multicolumn{1}{c}{ Variable } & Events observed $(\mathbf{n})$ & Events expected $(\mathbf{n})$ \\
\hline eGFR $\left(\mathrm{mL} / \mathrm{min} / 1.73 \mathrm{~m}^{2}\right)$ & & \\
$>90$ & 29 & 50 \\
$60-90$ & 122 & 186 \\
$30-59$ & 157 & 98 \\
$<30$ & 20 & 7 \\
DDRF & 15 & 3 \\
Total & 343 & 343 \\
\hline$\chi^{2}(4)=150.41 ; \operatorname{Pr}>$ chi $^{2}=0.0000$. & eGFR, Estimated glomerular filtration rate; \\
$D D R F$, dialysis-dependent renal failure. &
\end{tabular}

the DDRF group. An elevated logistic euroSCORE was associated with a prolonged cardiopulmonary bypass time. An eGFR of approximately $90 \mathrm{~mL} / \mathrm{min} / 1.73 \mathrm{~m}^{2}$ was associated with the best survival outcomes.

\section{DISCUSSION}

Using the sMDRD equation to categorize the preoperative renal dysfunction, we have evaluated the long-term outcomes of cardiac surgery. A single-center study of this size with specific outcome measures has not been performed.

The sMDRD method gives a more accurate estimation of renal function compared with that by the measurement of serum creatinine. The euroSCORE and others ${ }^{12}$ have used creatinine values greater than $200 \mu \mathrm{mol} / \mathrm{L}$ as a marker of decreased short-term survival. The GFR associated with a creatinine level greater than $200 \mu \mathrm{mol} / \mathrm{L}$ varies with age, gender, and race, and thus, potentially leading to an underestimation of the risk in the elderly.

Methods such as the 1 described by Cockcroft and Gault can lead to an overestimation of GFR in patients with endstage renal disease. The eGFR, estimated using the sMDRD formula, accounts for age as a variable.

The present study had a number of limitations. Our study was from a single center, and the results might not be 

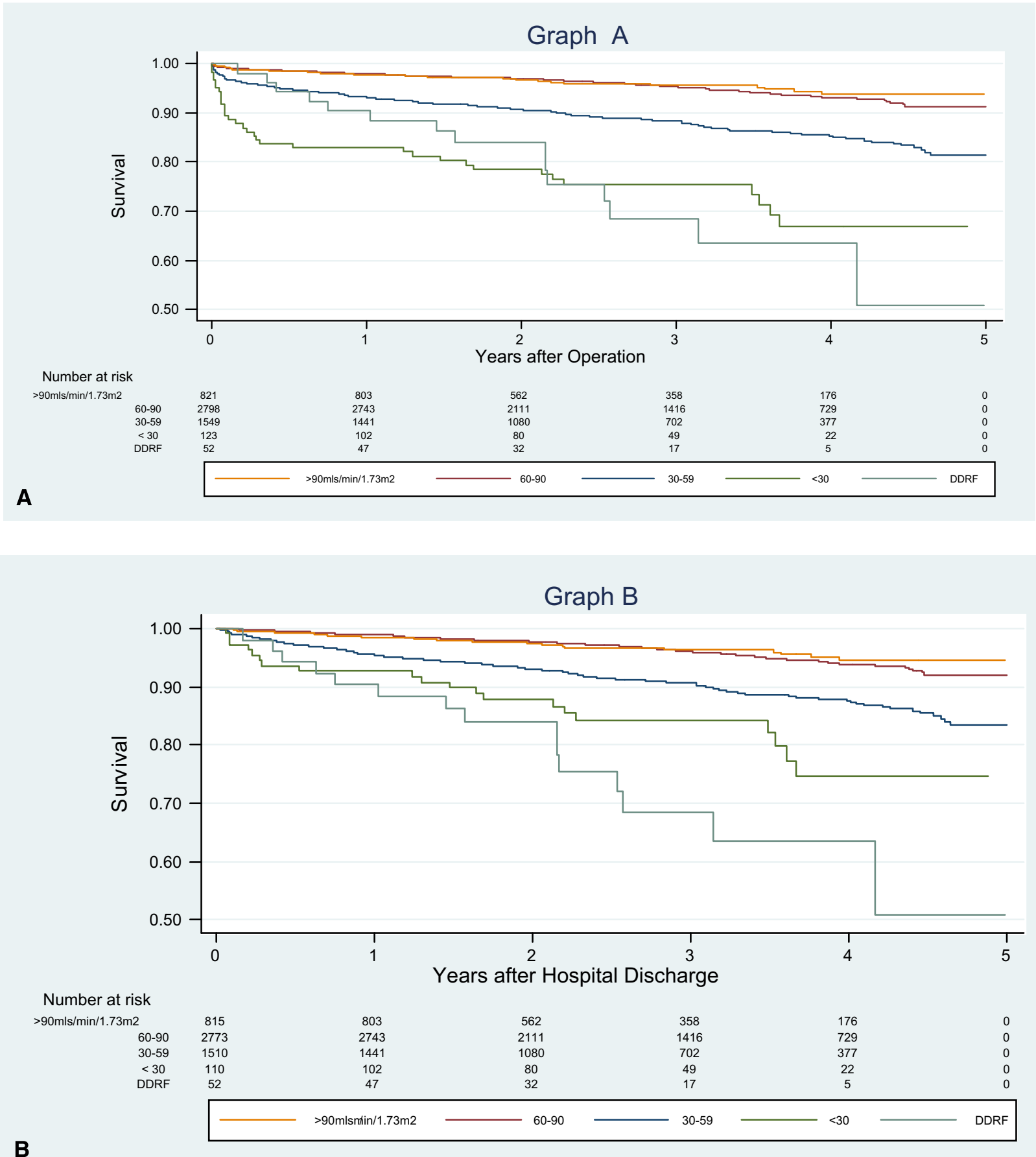

FIGURE 1. The survival of the study sample stratified by preoperative renal function using the simplified Modification of Diet for Renal Disease (MDRD) formula with follow-up data obtained from the National Death Index. A, The sample from the time of surgery. B, The actuarial survival for those discharged alive from the hospital. $D D R F$, Dialysis-dependent renal failure.

generalizable to other hospitals. A new scoring system, the euroSCORE II, ${ }^{6}$ has been recently validated. It includes variables such as the eGFR (using the Cockcroft-Gault method) and diabetes status. It has been shown that the previous model overpredicted short-term mortality. Its use in predicting long-term mortality has not yet been evaluated.
The mortality was $8 \%$ at a mean of 2.9 years, limiting the ability to define median survival. We used data linkage without a unique identifier to determine the vital status, for which the estimates of accuracy have varied from $89 \%$ to $98 \%$. This method has been used previously to estimate long-term survival after intensive care. ${ }^{16} \mathrm{We}$ did not 
TABLE 3. Cox proportional hazards model of the association of preoperative eGFR with long-term survival in patients discharged alive from hospital after cardiac surgery without and with risk adjustment

\begin{tabular}{|c|c|c|c|c|c|}
\hline Variable & HR & SE & $\mathbf{z}$ & $\boldsymbol{P}>|\mathbf{z}|$ & $95 \% \mathrm{CI}$ \\
\hline \multirow{2}{*}{\multicolumn{6}{|c|}{$\begin{array}{l}\text { Without risk adjustment } \\
\text { eGFR category } \\
\quad\left(\mathrm{mL} / \mathrm{min} / 1.73 \mathrm{~m}^{2}\right)\end{array}$}} \\
\hline & & & & & \\
\hline$>90$ & 1 & & & & \\
\hline $60-90$ & 1.2 & 0.27 & 0.98 & .326 & $0.81-1.91$ \\
\hline $30-59$ & 3.2 & 0.7 & 5.39 & 0 & $2.10-4.91$ \\
\hline$<30$ & 6.3 & 1.9 & 6.14 & 0 & $3.51-11.37$ \\
\hline DDRF & 10.7 & 3.55 & 7.08 & 0 & $5.53-20.47$ \\
\hline \multicolumn{6}{|l|}{ With risk adjustment } \\
\hline Comorbidity & & & & & \\
\hline Age $(y)$ & 1.036 & 0.007 & 5.53 & 0 & $1.02-1.05$ \\
\hline Vascular disease & 1.9 & 0.25 & 4.81 & 0 & $1.46-2.44$ \\
\hline COPD & 1.9 & 0.24 & 4.84 & 0 & $1.45-2.42$ \\
\hline Neurologic & 2.7 & 0.75 & 3.61 & 0 & $1.58-4.65$ \\
\hline $\begin{array}{l}\text { Ejection fraction } \\
30 \%-50 \%\end{array}$ & 1.8 & 0.23 & 4.88 & 0 & $1.44-2.34$ \\
\hline Ejection fraction $<30 \%$ & 1.9 & 0.47 & 2.77 & .006 & $1.21-3.1$ \\
\hline $\begin{array}{l}\text { Recent myocardial } \\
\text { infarction }\end{array}$ & 1.5 & 0.22 & 3.16 & .002 & $1.18-2.02$ \\
\hline \multicolumn{6}{|l|}{ Surgical complexity } \\
\hline CABG only & 1 & & & & \\
\hline Single valve & 1.07 & 0.2 & 0.39 & .7 & $0.75-1.54$ \\
\hline 1 valve + CABG & 1.3 & 0.21 & 1.66 & .1 & $0.95-1.78$ \\
\hline $\begin{array}{r}\geq 2 \text { valves with or } \\
\text { without } C A B G\end{array}$ & 1.9 & 0.39 & 3.32 & .001 & $1.31-2.89$ \\
\hline Aortic wall surgery & 1.6 & 0.41 & 1.78 & .075 & $0.95-2.64$ \\
\hline Reoperation & 1.7 & 0.26 & 3.4 & .001 & $1.25-2.27$ \\
\hline \multicolumn{6}{|l|}{$\begin{array}{l}\text { eGFR category } \\
\qquad\left(\mathrm{mL} / \mathrm{min} / 1.73 \mathrm{~m}^{2}\right)\end{array}$} \\
\hline$>90$ & 1 & & & & \\
\hline $60-90$ & 0.9 & 0.2 & -0.46 & .64 & $0.58-1.4$ \\
\hline $30-59$ & 1.6 & 0.37 & 2.01 & .05 & $1.01-2.5$ \\
\hline$<30$ & 2.6 & 0.81 & 3.03 & .002 & $1.4-4.79$ \\
\hline DDRF & 6.9 & 2.32 & 5.7 & 0 & $3.54-13.34$ \\
\hline
\end{tabular}

$C A B G$, Coronary artery bypass grafting; $C I$, confidence interval; $C O P D$, chronic obstructive pulmonary disease; $D D R F$, dialysis-dependent renal failure; $e G F R$, estimated glomerular filtration rate; $H R$, hazard ratio; $S E$, standard error.

measure known renal-specific prognostic factors such as urinary protein nor did we assess for microalbuminuria.

The Kaplan-Meier survival curves have demonstrated greater early mortality rates in the severe renal dysfunction group compared with the unexpectedly low rates in the DDRF group. This might have resulted from the patient selection practices, because the severe renal dysfunction group had a much greater logistic euroSCORE than the DDRF group. However, the DDRF group then showed a steep decline in survival, consistent with the published data from patients after myocardial infarction and cardiac surgery.

The 2 groups with an eGFR of 60 to 90 and greater than $90 \mathrm{~mL} / \mathrm{min} / 1.73 \mathrm{~m}^{2}$ have shown similar survival curves. A distinct decrease in survival was found at an eGFR of 30 to
$59 \mathrm{~mL} / \mathrm{min} / 1.73 \mathrm{~m}^{2}$. However, when the eGFR was adjusted for the severity of illness, operative factors, and diabetes status, a linear decrease was found in survival as the eGFR decreased.

In the present study, $62 \%$ of patients underwent coronary artery surgery alone and $38 \%$ underwent additional procedures. In contrast, Hills et al ${ }^{17}$ had $11 \%$ patients who underwent additional procedures, and Filsoufi et $\mathrm{a}^{13}$ had only $43.7 \%$ of 6449 patients who underwent isolated coronary artery bypass grafting.

The patients with more severe degrees of renal dysfunction underwent more complex surgery, which could lead to additional worsening of renal function (Table 1).

Filsoufi et $\mathrm{al}^{13}$ reported a similar finding, using a creatinine value of $2.5 \mathrm{mg} / \mathrm{dL}$ to define nondialysis-dependent renal failure.

There are several statistical points to note. The euroSCORE includes patient age and creatinine as variables and is widely used for risk adjustment in cardiac surgery. Hence, a multivariate model using the euroSCORE could reduce the ability to detect the effect of eGFR and might underestimate the long-term risk. However, the effect of eGFR remained statistically significant, even when the euroSCORE was included. We included a proportional hazards model, expressed as hazard ratios, with the patients with an eGFR greater than $90 \mathrm{~mL} / \mathrm{min} / 1.73 \mathrm{~m}^{2}$ as the reference group (Table 3). The Cox model is widely used for survival analysis and is considered robust for not meeting the assumption of proportional hazards. The overall fit might be improved by the use of fractional polynomial regression of continuous covariates, as described by Royston and Par$\operatorname{mar}^{18}$ or the use of cubic splines to model the baseline hazard at the expense of the complexity of the interpretation.

Previously, we have shown increased in-hospital mortality and increased hospital and intensive care unit lengths of stay for patients with renal dysfunction undergoing cardiac surgery. ${ }^{11}$ The present study has added to that work by demonstrating reduced long-term survival as the eGFR decreased. This has been seen in other studies ${ }^{19}$ of patients with moderate and end-stage renal failure. Others have shown improved survival in DDRF patients undergoing off-pump compared with those with undergoing on-pump $\mathrm{CABG}^{20}{ }^{20}$ Sajja and colleagues ${ }^{21}$ demonstrated the deleterious effect of on-pump CABG in the preoperative nondialysis-dependent renal failure patient population. They also concluded that SMDRD was a more sensitive investigation than the serum creatinine level for assessing renal insufficiency.

Stoves and colleagues ${ }^{22}$ concluded that the MDRD equation tends to underestimate the GFR in those with normal renal function $\left(\mathrm{eGFR}>90 \mathrm{~mL} / \mathrm{min} / 1.73 \mathrm{~m}^{2}\right)$. This can cause misclassification and lead to a decreased effect size in the mild category, resulting in less differentiation between the mild and normal categories. Despite this, the eGFR is 
widely accepted as a measure of preoperative renal function for this population. ${ }^{7,23}$

We have calculated the eGFR using the previously recommended equation in which the serum creatinine component is multiplied by 186 . This equation has since been modified $^{24}$ owing to discrepancies between the assay used to establish the formula and those now produced to standardized recommendations. The serum creatinine component is now multiplied by 175 . This could lead to misclassification. However, a good correlation between the 2 methods has been seen. ${ }^{23}$

\section{CONCLUSIONS}

Preoperative renal dysfunction as measured by creatinine and eGFR is an independent predictor of the interval to death for patients undergoing cardiac surgery.

The authors acknowledge and thank J. Johnson, data manager, intensive care unit, Associate Professor Adrian Barnett, statistician, and S. Smith, Cardiac Surgical Register Coordinator, for their contributions to our study.

\section{References}

1. Tong B, Stevnson C. Comorbidity of cardiovascular disease, diabetes and chronic kidney disease in Australia. Cardiovascular Disease Series, no. 28, Cat no. CVD 37. Canberra: Australian Institute of Health and Welfare; 2007.

2. National Cardiovascular Disease Database. The burden of chronic kidney disease. Canberra: Australian Institute of Health and Welfare. Available at: http://www. aihw.gov.au/WorkArea/DownloadAsset.aspx?id=6442459669. Accessed August 3, 2007.

3. Weiner DE, Tighiouart H, Stark PC, Amin MG, MacLeod B, Griffith JL, et al. Kidney disease as a risk factor for recurrent cardiovascular disease and mortality. Am J Kidney Dis. 2004;44:198-206.

4. Ferguson TB Jr, Hammill BG, Peterson ED, DeLong ER, Grover FL. A decade of change-risk profiles and outcomes for isolated coronary artery bypass grafting procedures, 1990-1999: a report from the STS National Database Committee and the Duke Clinical Research Institute. Society of Thoracic Surgeons. Ann Thorac Surg. 2002;73:480-90.

5. Higgins TL, Estafanous FG, Loop FD, Beck GJ, Blum JM, Paranandi L. Stratification of morbidity and mortality outcome by preoperative risk factors in coronary artery bypass patients: a clinical severity score. JAMA. 1992;267:2344-8.

6. Nashef SA, Roques F, Sharples LD, Nilsson J, Smith C, Goldstone AR, et al. EuroSCORE II. Eur J Cardiothorac Surg. 2012;41:734-45.

7. Cooper WA, O'Brien SM, Thourani VH, Guyton RA, Bridges CR, Szczech LA, et al. Impact of renal dysfunction on outcomes of coronary artery bypass surgery: results from the Society of Thoracic Surgeons National Adult Cardiac Database. Circulation. 2006;113:1063-70.

8. Bardakci H, Cheema FH, Topkara VK, Dang NC, Martens TP, Mercando ML, et al. Discharge to home rates are significantly lower for oc- togenarians undergoing coronary artery bypass graft surgery. Ann Thorac Surg. 2007;83:483-9.

9. Hein OV, Birnbaum J, Wernecke KD, Konertz W, Jain U, Spies C. Three-year survival after four major post-cardiac operative complications. Crit Care Med. 2006;34:2729-37.

10. Williams TA, Dobb GJ, Finn JC, Knuiman M, Lee KY, Geelhoed E, et al. Data linkage enables evaluation of long-term survival after intensive care. Anaesth Intensive Care. 2006;34:307-15.

11. Foot CL, Chinthamuneedi M, Fraser JF, Smith SE, Fayers T, Tesar P, et al. The association between preoperative eGFR and outcomes in cardiac surgical patients. Crit Care Resusc. 2009;11:184-90.

12. Devbhandari MP, Duncan AJ, Grayson AD, Fabri BM, Keenan DJ, Bridgewater B, et al. Effect of risk-adjusted, non-dialysis-dependent renal dysfunction on mortality and morbidity following coronary artery bypass surgery: a multi-centre study. Eur J Cardiothorac Surg. 2006;29:964-70.

13. Filsoufi F, Rahmanian PB, Castillo JG, Chikwe J, Carpentier A, Adams DH. Early and late outcomes of cardiac surgery in patients with moderate to severe preoperative renal dysfunction without dialysis. Interact Cardiovasc Thorac Surg. 2008;7:90-5.

14. Levey AS, Bosch JP, Lewis JB, Greene T, Rogers N, Roth D. A more accurate method to estimate glomerular filtration rate from serum creatinine: a new prediction equation. Modification of Diet in Renal Disease Study Group. Ann Intern Med. 1999;130:461-70.

15. Anavekar NS, McMurray JJ, Velazquez EJ, Solomon SD, Kober L, Rouleau JL, et al. Relation between renal dysfunction and cardiovascular outcomes after myocardial infarction. $N$ Engl J Med. 2004;351:1285-95.

16. Mullany DV, Foot CL, Smith SE, Johnson J, Barnett AG. Methods and preliminary results for a data linkage project to determine long-term survival after intensive care unit admission. Crit Care Resusc. 2009;11:191-7.

17. Hillis GS, Croal BL, Buchan KG, El-Shafei H, Gibson G, Jeffrey RR, et al. Renal function and outcome from coronary artery bypass grafting: impact on mortality after a 2.3-year follow-up. Circulation. 2006;113:1056-62.

18. Royston P, Parmar MK. Flexible parametric proportional-hazards and proportional-odds models for censored survival data, with application to prognostic modelling and estimation of treatment effects. Stat Med. 2002;21: 2175-97.

19. Chikwe J, Castillo JG, Rahmanian PB, Akujuo A, Adams DH, Filsoufi F. The impact of moderate-to-end-stage renal failure on outcomes after coronary artery bypass graft surgery. J Cardiothorac Vasc Anesth. 2010;24:574-9.

20. Shroff GR, Li S, Herzog CA. Survival of patients on dialysis having off-pump versus on-pump coronary artery bypass surgery in the United States. $J$ Thorac Cardiovasc Surg. 2010;139:1333-8.

21. Sajja LR, Mannam G, Chakravarthi RM, Sompalli S, Naidu SK, Somaraju B et al. Coronary artery bypass grafting with or without cardiopulmonary bypass in patients with preoperative non-dialysis dependent renal insufficiency: a randomized study. J Thorac Cardiovasc Surg. 2007;133:378-88.

22. Stoves J, Lindley EJ, Barnfield MC, Burniston MT, Newstead CG. MDRD equation estimates of glomerular filtration rate in potential living kidney donors and renal transplant recipients with impaired graft function. Nephrol Dial Transplant. 2002;17:2036-7.

23. Moore EM, Simpson JA, Tobin A, Santamaria J. Preoperative estimated glomerular filtration rate and RIFLE-classified postoperative acute kidney injury predic length of stay post-coronary bypass surgery in an Australian setting. Anaesth Intensive Care. 2010;38:113-21.

24. Mathew TH, Johnson DW, Jones GR. Chronic kidney disease and automatic reporting of estimated glomerular filtration rate: revised recommendations. Med J Aust. 2007;187:459-63. 